\title{
Marine Culture of Northeast Vietnam: Approaching from the Theory of Culture Ecology
}

\author{
Nam Thanh Nguyen \\ Doctor of Culturology, Faculty of Cultural Studies, Hanoi University of Culture \\ (Hanoi, Vietnam) \\ E-mail: namnt@huc.edu.vn \\ https://orcid.org/0000-0003-4732-809X
}

Nguyen, Nam Thanh (2020) Marine Culture of Northeast Vietnam: Approaching from the Theory of Culture Ecology. Future Human Image, Volume 13, 2020: 66-75. https://doi. org/10.29202/fhi/13/7

The purpose of this paper is to contribute to further clarifying the characteristics of marine culture in the Northeast of Vietnam from the theory of cultural ecology. The research results of the article will also be a scientific basis to contribute to the study of Vietnam's sea and islands from the science of culture. In order to carry out this research, the author uses an analytical-synthesis method, which is used to deeply understand the research object, combining a comparative approach to show the similarities and differences between the marine culture of Northeast Sea and some other areas in Vietnam. The author attaches special importance to the practical survey method: participating in cultural activities of residents of some localities in the Northeast Sea of Vietnam (such as Quan Lan Island, Co To Island, Cat Ba Island...), and conducting interviews with people for the purpose of truly describing phenomena related to marine culture.

Previous studies in Vietnam only focused on describing the appearance. They stated the values of Vietnamese coastal culture and some localities in the Northeast, but the theory of approach in marine culture research is unclear. This research uses the theoretical framework of cultural ecology to affirm: the people in the Northeastern region of Vietnam with their thinking have created ways to adapt to the natural environment and always creating material and spiritual values that bring about the highest adaptation to nature to benefit their life activities. The research results of this article can be used as a reference for the culture of the islands in the Northeast in particular and the Vietnamese culture in general, including theoretical research on marine culture, as well as the analysis of marine cultural characteristics from cultural ecology theory.

Keywords: marine culture, northeast Vietnam, cultural ecology

Received: March 1, 2020; accepted: March 12, 2020

(C) Nguyen, Nam Thanh, 2020 


\section{Introduction}

Culture is ultimately the result of the individual and community adapting to the natural and social environment around them to survive. Cultural ecology discusses the relationship between culture and environment, considering the environment as an important factor. People experience their lives and have to adapt to the environments through cultural contexts. Vietnam is a country known to the world for its richness and cultural diversity, in which it is impossible not to mention the marine culture of the Vietnamese people who live along the coast with a length of more than $3,000 \mathrm{~km}$. from the North to the South, and about 1 million $\mathrm{km}^{2}$ of sovereign waters have created many distinctive marine cultural imprints. Vietnam is a Sea country. Vietnam has the longest coastline of the ten countries surrounding the South China Sea with over 3,000 large and small islands, with a land area and sovereignty many times larger than on the mainland. Besides the mainland, the sea and islands are a geographical and cultural feature of Vietnam culture and civilization, an important cultural and ecological value of the Northeast. For the coastal community, the marine ecosystem plays a significant role in the socio-economic development of this land, as well as the environment and contributes to creating a cultural impression. It is in the process of impacting on nature, especially the marine environment, that the Northeastern people have constantly adapted and transformed nature to the purpose that is most beneficial to them, thereby creating material values and the spirit of ensuring the survival and development of the residents, on the other hand, showing the understanding and manners of the natural environment.

\section{Marine Culture of Northeast Vietnam: Approaching from the Theory of Culture Ecology}

Research on marine is a recent topic that has received the attention of many fields of study such as geography, economics, politics, history, and especially anthropology. Maritime anthropology is a discipline of social anthropology focusing on fishing community groups, with marine knowledge and marine livelihoods, and social community. It was only in the 1970s that the term 'maritime anthropology' gained some currency as a sub-discipline focused on human-marine relations - extraordinary diversity. Anthropologists interested in "maritime anthropology" have focused on three subjects: modern documented, shipboard life, and prehistoric marine adaptations (Acheson, 1981). Acheson saw the significance of maritime anthropology as a sub-discipline in the shared interest in how human beings adapt to making a living from the sea, and in the idea that "fishing poses similar problems the world over" (Acheson, 1981).

Also, from an anthropological perspective, foreign authors have been interested in researching and teaching about Marine Anthropology in Vietnam. Tana Li, an expert on Asian history, pointed out some differences in the marine culture of the two regions of the North and the Central (Li, 2006). In 2010, with an anthropological approach, Tuyet Phan Thi Yen and other lecturers of the University of Social Sciences and Humanities, Ho Chi Minh city of Vietnam, created the first research group on Vietnam's Marine Anthropology. Akifumi Iwabuchi, who is the Professor of Marine in Tokyo University of Marine Science and Technology (Japan), has introduced the Marine Anthropology as a subject to the students of the Faculty of Anthropology. Based on fieldwork and maritime research conducted in Southeast and East Asia, the South Seas, and Europe since 1986, he published numerous articles and books, which deal mainly 
with the insular people, their material culture, and their colonial history. Marine Culturology is directly related to Marine Anthropology, Marine History, Underwater Archeology, Study of Maritime Art, and Study of human adaptation toward the marine environment. Thus, in the study of marine anthropology, it also includes the study of marine culture (marine culturology / marine culture). In the most general sense, the field of Marine Anthropology studies all the issues of human activity (directly or indirectly) attached to the sea. At the core of the subjects of marine anthropology and marine culture are fishermen communities and people living on the sea and islands through their economic, cultural, and social activities, studying their children's adaptations. People with marine ecological environment, policies on strategic management of marine resources and environment, cross-cultural issues in the seas, and islands of regions.

Over the past 20 years in Vietnam, there have been many marine research documents from the approach of cultural research. In 1996, the Institute of Southeast Asian Studies in Vietnam mentioned the massive role of the sea in the formation of the Vietnamese today, especially the migration of the Austronesian inhabitants to the living areas of Vietnamese people before. The research Fishing community in Vietnam is the first work to mention a sufficient theoretical basis of the characteristics and properties of Vietnamese marine culture. This research gives the most general content about Vietnamese fishermen, such as the process of forming fishing communities, the material, and the spiritual life of the fishermen ... And especially, in the author's work, fishing communities do many different types. However, the author focuses on the in-depth study of the life of coastal fishermen in the Central and Southern regions, and the Northern part mentioned but not much (Thieu Nguyen Duy, 2002). And another researcher affirmed the typical elements in the culture of coastal residents of Vietnam in 2010 (Thinh Ngo Duc, 2010).

From the sources related to the research object of the article, it has been shown that there are not many research works connecting the marine culture and theoretical issues in specific localities. The outstanding theoretical contribution of the previous works is the system and clarifies concepts related to marine culture, marine anthropology with the participation of many authors from other research subjects together. This paper will give an understanding of the constituents and characteristics of marine culture in Northeast Vietnam from the perspective of cultural ecology.

\section{Overview of theoretical issues and research sites}

All maritime activities including large vessels, small rafts, shipwrecks, shipyards, docks, wharves, warehouses, canals, lighthouses, lifesaving stations and help with settling location, coastal sites, naval facilities and exhibits related to contemporary activities ... can all be considered marine culture (Spirek \& Scott-Ireton, 2003). Besides, there are many other concepts of marine culture. Speaking of marine culture is about the lifestyle of the communities along the coast exploiting (and participating in) the exploitation of aquatic resources in rivers and seas in general for subsistence (Thieu Nguyen Duy, 2007). From the viewpoint of cultural anthropology, marine culture is understood as a system of human knowledge about the marine environment, the values and symbols drawn from the activities living in that environment. Along with it are perceptions of human behavior, rituals, customs, habits compatible with the marine environment (Thinh Ngo Duc, 2010). The common characteristics of these concepts confirm that marine cultural elements are considered as a form of ecological culture or a set of parts of the culture of a residential community or a suburban coast. Marine culture includes 
elements of material, spiritual, and social values created by coastal communities in the process of interaction between people and islands. The directions on marine culture in Vietnam currently focus on the history of marine culture, marine cultural space, cultural actors or communities living in the marine and their cultural creation activities; elements of marine culture such as food, houses, local languages, literature, art, religion, customs and rituals related to the marine.

The ancient Greek word of "ecology" is "Oikos," which means the dwelling, residence, and habitat of all living things, including humans. The ecological environment is the home of species, especially the habitat of humans. From an ecological perspective, the ecological environment includes many elements: terrestrial, atmospheric, atmospheric, and other species. These are important elements indispensable in an ecosystem. The theory of Cultural Ecology appeared in 1950, focusing on studying the relationship between people - environment culture, associated with the name of American anthropologist Julian Steward (1902 -1972). According to his cultural and ecological perspective, the rudimentary societies with the survival technology are, the more they depend on nature. Because in societies with a high level of science and technology, people have relatively conquered nature, captured nature to serve their will and then in that ecological context, humans have experienced the experience of creating cultural and life skills of our community based on the psychology and identity of the national culture. The method of cultural ecology of Julian Steward aims at clarifying the relationship between culture and the environment that views people as being adaptable to the environment through culture, which in turn, is influenced by culture. The great impact of the environmental resources on human use. Steward specified three steps in the investigation of the cultural ecology of a society: (1) describing the natural resources and the technology used to extract and process them; (2) outlining the social organization of work for these subsistence and economic activities; (3) tracing the influence of these two phenomena on other aspects of culture (Barfield, 1997).

From the viewpoint of Julian Steward, cultural ecology in Vietnam is also recognized by researchers as forms of culture formed and developed corresponding to certain environments such as marine ecology, islands, delta ecology, plateau ecology (Steward, 1995). When it comes to the constituents, researchers often assert that Southeast Asia in general and Vietnam, in particular, are a complex of wet rice culture, including mountain culture, delta culture, and marine culture are intertwined in the process of survival and development. Ethnic groups who have been living for a long time in the ecological environment in the territory of Vietnam, they will have experiences, adaptations, creativity, formation of life skills and expression of psychological nuances as well as forms of culture following the ecological environment.

\section{Overview of the northeastern sea of Vietnam}

Vietnam is a large sea country located on the west coast of the East Sea. In the East Sea, related to Vietnam, there are two large gulfs, namely the Tonkin Gulf in the Northwest, about $130,000 \mathrm{~km}^{2}$ wide, and the Gulf of Thailand in the Southwest, with an area of about 293,000 $\mathrm{km}^{2}$. This is the only sea connecting the two oceans - the Indian Ocean and the Pacific Ocean. Climate regime in the northeastern region of Vietnam is characterized by a tropical monsoon climate with cold winters. From the North to the South of Vietnam, there are 28 coastal provinces and cities, including the Northeast coastline mainly belong to Quang Ninh and Hai Phong province. Hai Phong has a coastline of over $125 \mathrm{~km}$, including the coast surrounding offshore islands, spanning seven districts, adjacent to Quang Ninh in the North and Thai Binh 
in the South. The beach has a concave curve of the Gulf of Tonkin, low and flat, composed mainly of mud and sand made by five main estuaries. Off the coast of Hai Phong, there are many islands scattered all over the sea. The largest is Cat Ba Island, and the furthest is Bach Long Vi Island. Cat Ba Island is the only large limestone island of Vietnam, on the islands with tropical forest ecosystems still retain high biological diversity. Cat $\mathrm{Ba}$ - Long Chau limestone archipelago has a unique landscape, with a high potential for nature conservation and contains global values that have not been exploited and used commensurately with the potential. Bach Long Vi is Vietnam's most remote island in the Tonkin Gulf, with a strategic position and special importance to ensure national sovereignty over the sea and national defense and security. Quang Ninh is the gateway to the sea of the whole Red River Delta - the Northern midland and mountainous region with more than $250 \mathrm{~km}$ of coastline, more than $6,000 \mathrm{~km}^{2}$ of sea surface, over 1,000 $\mathrm{km}^{2}$ of island area, Quang Ninh province has eight districts of the island. Co To is a special district consisting of nearly 50 small and large islands playing off the farthest offshore line, with the smallest area, the smallest population, but retaining an extremely important outpost position in front of the Northeast.

The Northeastern sea of Vietnam was formed long ago in the history of the nation. Archaeological findings show that Soi Nhu and Cai Beo are the primary traces of the sea in the post-Neolithic period. The East has formed a thriving Ha Long culture. The coastal residents and islands of Northeast Vietnam over 4000BP - 3000BP have been discovered by archaeologists to live with the sea, to conduct economic activities, to exploit the sea (mollusk exploitation: oysters, snails, clams, oysters, scallops), fishing and other seafood, developing the fishing economy to an unprecedentedly high level: developing grinding tools, vehicles by rafts, fishing gear, pottery creations..., establishing an outdoor lifestyle, and possibly step by step promoting a productive economy. The history of residence and survival of people living in Cat Hai island district (Hai Phong) is also of interest to archaeologists through research and surveys on prehistoric and primitive periods history on the island. The results show that there are up to 15 vestiges of ancient people on the island, such as Eo Am cave in Hien Hao commune, Tung Ba of National Park, Bo Da, Khoai Mui of Tran Chau commune, Ang Giua of Viet Hai commune. Especially the Cai Beo site was discovered in 1938 by a French archaeologist, through many excavations and results of carbon dioxide analysis said that the ancient Vietnamese people here appeared over 6,000 years. Cai Beo vestige has a great historical value affirming that ancient Vietnamese people have lived in this land since ancient times.

Maritime fishing communities can be defined, from a functional perspective, as human groups who have an emphasis on the exploitation of maritime environments. They may not be exclusively dependent on the maritime environment (Prieto, 2016). Residents of the coastal areas of Hai Phong and Quang Ninh in the northeastern region of Vietnam have a complex formation and composition. Residents of the coastal villages of Hai Phong are formed from two main sources: the native Vietnamese and the people from other places who have connections with the Malay linguistic language. The ancient Hai Phong sea area is located on the way to the South, and whether or not this ethnic group congregates in the seaside villages, this view is still being studied by ethnologists to find the solution. However, Vietnamese people in history have tended to move from the mountains to the plains and head to the sea, where they encroach on the sea to settle there. Therefore, the majority of coastal residents live in communities that not only make a living by fishing, where they still have the imprint of agricultural production. In the history of the coastal area of Quang Ninh, besides the part of the indigenous people 
who had been the owners of the early metal cultures, this land also witnessed population groups from the midlands and fields by exploring the seas. Besides, there are a number of people specializing in fishing, typically the Tran and Mac families, who are coastal residents, after settling in Thai Binh, Nam Dinh, and a part in Quang Ninh sea. Therefore, one of the characteristics of the population community in the northeastern region of Vietnam is the chaos of migrations to new lands.

\section{Marine culture in the Northeast is formed by techniques and methods of coastal and island communities}

It can be seen that for residents of the Northeast of Vietnam, when their lives and careers are always associated with the sea, the seas and occupations are very important to their daily lives. The occupations of marine residents related to fishing. The productivity of cruises depends not only on the weather of the sea and the water calendar but also a lot of indigenous knowledge. Fishermen in the sea often divide their fishing activities into coastal areas and offshore areas. In the coastal areas, fishermen often develop clam and scallop fishing. In the estuaries intertwined with saltwater and freshwater, there are many methods of interwoven. In the form of offshore fishing, fishermen use nets to catch fish. In addition, coastal people also have jobs such as shipbuilding, trading... Because of the convenient system of estuaries to the sea, people in the Northeast Sea have historically reached out to the sea to trade and exchange with the outside, as in the case of Van Don (Quang Ninh) has become a major seaport of the area since the $11^{\text {th }}$ century. It can be seen that for the people of the Northeast Sea region when their lives and careers are always associated with the sea, the sea and their jobs are very important to their daily lives. The system of occupations has been very diverse, including fishing, aquaculture and seafood processing activities, shipbuilding, boat and seagoing activities; fishing activities; salt making, trading activities. Each professional activity has its own techniques and methods of exploitation, but it reflects how the community utilizes, exploits, behaves, and copes with the environment itself.

\section{Maritime culture in the Northeast is expressed through human behavior patterns related to the use of the marine environment}

Viewed from the perspective of creative cultural subjects, the islanders have relationships to behave. It is the relationship with the natural environment, the social environment, and the relationship with himself. Marine and island culture is the result of a creative process of islanders and settlers of these relations (Ben Nguyen Chi, 2015). In the theory of cultural ecology, there is a special aspect that is the system of folk knowledge that humans create and accumulate in the cultural and ecological interaction that humans exist. For fishermen in the Northeast Sea, the system of folk knowledge is quite rich, reflecting the characteristics of the fishermen's life, the fishery still depends much on nature, especially the knowledge of whether to go to the sea or experiences for fishing. Fishing is a year-round hard work, and the most permanent danger is that in the past, when the means of fishing were mainly by hand, there was no machinery, modern technology, the folk knowledge about weather and the environment is essential. Nature plays a prerequisite for fishing trips to the fishing grounds. They consciously accumulate weather-related experiences to remind each other of the times when the sea is not calm, the winds are not quiet, or the calculations are planned in letting go. Occupational habits 
have given communities of coastal areas with keen eyes and sensitive ears to see the sky, the moon, or the tide. The sea is not always filled with storms and dangers, but also contains peace and an endless source of life for people, so from the depths of the mind of people living with the sea, there are always two parallel attitudes: on one side, it is fearful and wants to conquer the mysterious vastness of the open sea, but on the other hand, it is very knowledgeable and grateful for the sea that has brought them a source of life. When fishermen have not applied scientific advances, grasping the laws of nature is extremely necessary because if you do not care about the smallest things, the vast sea can be dangerous to life. People in Hai Phong and Quang Ninh often rely on the experiences inherited from their ancestors about the weather predictions and experiences drawn from themselves over many years of fishing. The days of calm waves sea are good days to go fishing. On days when the weather fluctuates severely, they have to come home during the day. Because if they go too long and meet the changing climate, small boats, limited human resources, they will not be able to come back to the land. In each locality, fishermen also have sayings and songs about the water calendar - that is, the ebb and flow of the water. The day when the water begins to rise and fall is called the water day. Knowing this rule of up and down helps fishermen track the changes of nature as well as have reasonable plans for a sea trip.

In addition to the way of dealing with the natural environment, the fishery has formed in the Northeastern fishermen the typical behavioral relations related to family organizations and clans. For residents living on fishing in the sea, the family is the basic social unit. Due to the nature of the lifestyle based on the resources brought from the sea, the fishermen's family is an autonomous economic unit, mainly operating for two generations. Living in the marine environment since birth, some children who have been able to do many things such as adults, participate in fishing nets or fishing nets, can also rowboats. The division of work in the family is quite clear; whenever fishing, the husband steers, the wife or the rowing dog behind the nose. When catching a net, the wife drives, and the husband drops the loss. If catching fish, if there is no merchant boat to buy on the spot, then both husband and wife and their older children will bring them to shore for sale. Or some families have a clear division of labor: going to the sea is for men and women at home to do other sea-related jobs such as raking sand (Quan Lan beach) or drying, processing seafood variables that ships can catch. Ms. N.V.T, a woman, living in Quan Lan Island, said: "The land of devotion is the coast of Quang Ninh, especially Minh Chau and Quan Lan communes. This place is also the land with the most delicious figs. Devourers live in sandy beaches with ebb and flow. The devotees who devote themselves are mainly women, requiring experience, technique, and artistic movements like dancers on the sand."

Although they make a living by fishing, people are always aware of their lineages. Families of the same lineage often go to sea together in certain fishing grounds. It is necessary to go along, both to support each other in fishing and to help each other when difficulties are caused by sea storms or other risks that seafarers often face with. However, their self-sufficiency and self-reliance are very high. The spirit of community blood, the sense of "a drop of blood digging more than water," shows very clearly in fishermen. With residents going to the beach, where boats can be safely and secluded, often gather boats of families with father, son, and relatives. 


\section{Marine culture in the Northeast has formed specific cultural aspects related to the sea}

The natural environment indirectly affects the formation of cultural components. The adaptation of cultural owners to the environment and, in turn, cultural owners that have the effect of changing the natural environment will be the basis for creating a cultural character of a land.

Eating and drinking is an essential need to sustain human life. But eating not only to satisfy the needs of hunger and thirst but is also an expression of culture - culinary culture. In the Northeast Sea, due to the life dependent on the open sea, the life of the people relies on boats, nets; the sea is quiet, "the rice is full, the fish is full of the pot," the rough sea is "stop rowing the pots"; business depends on the water, the sky breaks down, so the previous food was always deprived and difficult. Besides, there are many risks from natural disasters and storms that often threaten the lives of people. Living in extremely difficult circumstances, people here are worrying about workday at the same time, having to work hard at the same time and have to tighten their calculations in every expense and food. The concept of simple eating "whatever you eat," not picky in processing and enjoying from here, has been formed. The typical food in the meals of families of Hai Phong — Quang Ninh people is fish — the material available during the fishing process. Fish is also a raw material for residents to make traditional culinary products fish sauce. Most fishermen prefer to use small fish with low nutritional value. The tradition of salty food is also expressed in many types of fish sauce, which are processed by residents such as shrimp paste, fish sauce, etc., which have become specialties of the sea. This practice is consistent with the loud, definitive and strong eating spirit of the people in the sea as "fast food." The rice is served, not stretched out, and finished eating right up. Cuisine is the aspect most strongly influenced by natural conditions and shows the adaptation of people here to the sea. In the fishing, the island districts of Van Don, Co To, Quang Yen (Quang Ninh), or Cat Ba (Hai Phong) all have famous seafood such as squid, comedy, bored, paternal. This product is often used on the Tet holiday or used to be gifts or transporting to other regions or selling to tourists.

Fishermen in Quang Ninh — Hai Phong are also creative forces and circulating folk literature treasure about the rich sea. Ancient stories, legends, proverbs, folk songs, dances, including songs related to daily life and fishing experiences, enrich the spiritual life of fishermen. The fishermen in Van Don (Quang Ninh) have many proverbs related to the sea. They said, "On the tenth day of the tenth month, the anniversary of the boy's son; If they want to eat poor fish, they will go to the sea." (March, it is spring, the weather is clear, the sun is warm, the people working in the sea after the Tet holiday and the long festival, anxious to go to the sea. But be careful because in March there are often strong winds and it is hazardous). In some localities, there are also forms of ritual folk songs and folk love songs. In Van Don area, people still sing chèo đuòng (ví singing): this is a love-exchange singing style in the form of reciprocal between the two boys and girls of fishermen in the river and sea area. The singing takes place on a boat, at a river pier, or in a village festival. Through the lyrics, they express their feelings about life, about loyalty, about the love of couples.

The legend of the northeastern sea of Vietnam reflects the folk beliefs, including the worship of the sea god. Belief in the sea god reflects the awareness of the sea as a living and working environment, a place to convey the thoughts, feelings, and aspirations of fishermen. Subsistence activities depend on many natural risks, so fishermen in Quang Ninh coastal area have an essential spiritual element, which has formed a folk belief system related to 
the fishing career sea. This belief has a long history, originating from the fishermen's desire to pray for each peaceful trip to the sea, catching a lot of shrimp and fish. In addition to the sea gods, Quang Ninh fishermen also worship the drowning manifestations: Goddess Cua, Goddess Men, Goddess Hang, or as worshiping Pham Tu Nghi are a good general of the Mac Dynasty... Quang Ninh people are very bureaucratic, directing people to a good life, warm and compassionate, with the effect of connecting the community. Therefore, the marine worship is associated with folk festivals, an opportunity for fishermen to practice community cultural activities. The folk legends also made the festivals more shimmering legend. With these characteristics, Quang Ninh coastal folklore has its own unique values that serve as a mirror for the formation and development of the soul of Quang Ninh people. There are also many festivals with unique sea markings. Cat Hai also has many unique festivals. In Cat Hai island district (Hai Phong), there is a temple festival of Hien Hao commune held on January $12^{\text {th }}$ in association with the legend of Goddess $\mathrm{Ba}$, a saint who takes care of the people, teaches people how to plant, weave, how to catch shrimp and fish. The traditional boat racing festival in Cat Hai town was held on January $21^{\text {st }}$, rooted in the spiritual aspirations of seafarers, Dong Hai Dai Vuong God, the deity who governs the Eastern Sea of the Country, who is blessed for a favorable rainy year, favorable weather for shrimp and fish.

\section{Conclusions}

The culture of the northeastern region of Vietnam is a culture of an island region with a long history, similarities in population, socio-economic development level, and cultural exchange. Experiencing the process of labor and creativity, the people of the Northeastern islands have created typical cultural values imprinted by the sea. Thus, cultural ecology is the way that people use culture to adapt and make use of the specific natural environment in the context of the culture of the land. It is the process of impacting and transforming nature to create a better living environment. Through the adaptation of the people to the geographical environment of landscape and mutual cultural influence, they have expressed the psychological characteristics, ethnic culture, and formed the characteristics of regional culture. In the process of formation, survival, and development, people in the northeastern sea of Vietnam have constantly created a fairly rich and diverse marine cultural tradition. In the current period, under the impact of new livelihood methods, the sea cultural values of the people here tend to change, but not lose and are being preserved and promoted.

\section{References}

Acheson, James M. (1981) Anthropology of Fishing, Annual Review of Anthropology.

Barfield, Thomas (1997) The Dictionary of Anthropology, Oxford: Blackwell.

Ben Nguyen Chi (2005) Marine and island culture of Vietnam: values and approaches. Culturology, Vol.17, 11-28.

Li, Tana (2006) A View from the Sea: Perspective on the Northern and Central, Cambridge University.

Prieto, Gabriel (2016) Maritime Anthropology and the Study of Fishing Settlements in Archaeology: A Perspective from the Peruvian North Coast. Human - social science: History, Archaeology \& Anthropology, Vol.16.

Steward, Julian (1995) Theory of Culture Change. The Methodology of Multilinear Evolution, University of Illinois Press, Urbana. 
Thinh Ngo Duc (2010) Coastal traditions of Vietnamese culture. Culture and Art, Vol. 316, $15-21$.

Thieu Nguyen Duy (2002) Fishing community in Vietnam. Hanoi: Social Sciences Publishing House.

Thieu Nguyen Duy (2007) Reflecting on marine culture in Vietnam. Culture and Art, Vol.10, 28-30

Spirek, James D., and Della A. Scott-Ireton (2003) Submerged Cultural Resource Management, Preserving and Interpreting Our Maritime Heritage. New York: Kluwer/Plenum Publisher. 